Opinión

\title{
LA PREVENCIÓN, FASE CERO EN LA GESTIÓN DEL RIESGO: ¿SE PODRÍA HABER EVITADO PARTE DE LOS DAÑOS DEL COVID19 CON PREVENCIÓN?
}

Montserrat Ferrer Julià ${ }^{*}$

¿Se imaginan la magnitud del terremoto o inundación que tendría que acontecer en España para que el número de víctimas mortales superase las más de 25.000 que lleva esta pandemia del Covid-19? Pero un terremoto es un fenómeno natural impredecible en el tiempo. Sin embargo, este desconocimiento en el cuándo, no impide conocer dónde van a suceder los fenómenos de este tipo. De ahí que un gran número de estudios de amenazas naturales tengan como resultado una cartografía en la que se señalan aquellas zonas del territorio que tienen una mayor probabilidad de sufrir un evento que pueda causar daños, de mayor o menor magnitud.

Estos mapas se convierten así en una herramienta fundamental en la planificación territorial como herramienta de prevención y forman parte de la primera etapa básica de la gestión de las amenazas naturales y sus riesgos asociados. Para poder minimizar los daños de un fenómeno natural y facilitar la recuperación a la normalidad, es preciso que la sociedad se haya preparado previamente para saber qué hacer. Es por tanto necesario conocer el tipo de eventos que pueden suceder en una zona, su posible extensión, qué puntos de reunión son seguros para iniciar una evacuación, entre otros. Es un sistema de prevención tan simple y lógico que a nadie extraña que de vez en cuando se realicen, por ejemplo, simulacros de incendios en lugares públicos como en colegios, en donde los niños aprenden hacia dónde dirigirse en caso de siniestro.

Estos ensayos no hacen disminuir el número de incendios, pero sí que facilitan una mejor gestión del operativo durante un posible evento. Sin embargo, aunque esta educación en prevención funciona, no está claro por qué con otro tipo de eventos naturales extremos no se aplica.

¿Se podría haber evitado parte de los daños del COVID19 con prevención? Por supuesto, desde que apareció en China en diciembre de 2019 y se supo de su fuerte propagación en Italia, se sabía que aumentar la distancia social y lavarse las manos era algo básico, pero, aun así, unas normas tan simples no se difundieron ni promovieron por ningún tipo de Administración (estatal, regional o local) hasta que los números de contagiados aumentaron considerablemente.

Por desgracia, esta situación no es anormal cuando se trabaja en este tipo de fenómenos. Demasiados casos en la gestión de riesgos muestran poblaciones que no saben cómo reaccionar cuando un volcán próximo está activo (hacia dónde dirigirse, por ejemplo), viviendas que se edifican sobre terrenos que han sufrido inundaciones anteriormente o edificios que se construyen sin seguir la normativa sismo-resistente en zonas susceptibles de terremotos.

Por mucho que avancemos en el conocimiento, los fenómenos naturales seguirán sucediendo, solo la cuantía de sus daños dependerá de la capacidad de prevención de las sociedades. La prevención, el estar preparados para estos eventos, es siempre la solución que disminuirá los efectos adversos de todo tipo. La inversión en prevención supone muy poco dinero en comparación con las cuantiosas pérdidas económicas que generan los desastres, pero, aunque es una lección aprendida, parece ser que todavía no es un conocimiento asimilado por nuestra sociedad.
1. Programa de Máster en Riesgos Naturales, Facultad de Ciencias Biológicas y Ambientales, Universidad de León, León, España.

*Autor de correspondencia: mferj@unileon.es

\section{RECIBIDO}

12 de mayo de 2020

\section{PUBLICADO}

1 de julio de 2020

\section{Formato cita}

Recomendada (APA): Ferrer Julià, M. (2020). La Prevención, Fase cero en la Gestión del Riesgo: ¿Se podría haber evitado parte de los daños del COVID19 con prevención? Revista de Estudios Latinoamericanos sobre Reducción del Riesgo de Desastres REDER, 4(2), 125.

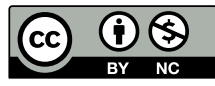

Todos los artículos publicados en REDER siguen una política de Acceso Abierto y se respaldan en una Licencia CreativeCommons Atribución-NoComercial 4.0 Internacional.

Revista de Estudios

Latinoamericanos sobre Reducción del Riesgo de Desastres (REDER)

Diseño: Lupe Bezzina Tipografía: Hospital 